\title{
Diseño de un amplificador de potencia para comunicaciones inalámbricas utilizando tecnológica microcinta y Microwave Office
}

\section{(Design of a power amplifier for wireless communications using microstrip technology and Microwave Office)}

\author{
Christian Tipantuña ${ }^{1}$, José Antonio Estrada ${ }^{1}$, Juan Carlos Estrada ${ }^{2}$, Carla Parra $^{3}$
}

\section{Resumen:}

En el presente artículo se realiza una descripción detallada de los parámetros y procedimientos que deben ser considerados en el diseño de un amplificador de potencia con tecnología microstrip utilizando el software de diseño AWR Microwave Office ${ }^{\mathrm{TM}}$; en específico, en el diseño se considera una frecuencia central de $14 \mathrm{GHz}$, pero los mismos principios y fundamentos pueden ser aplicados y tomados en cuenta en posteriores diseños y en diferentes frecuencias. En el diseño se considera como elemento activo un transistor de tipo MESFET y redes simultáneas de adaptación de impedancia de entrada y de salida. Los valores de los diferentes parámetros en cada etapa son calculados y analizados utilizando la herramienta de simulación AWR Microwave Office ${ }^{\mathrm{TM}}$. Al final del documento se muestra el diseño del amplificador tanto en dos y tres dimensiones y con todos los elementos necesarios para garantizar su funcionalidad.

Palabras clave: amplificador de potencia; redes de adaptación; microstrip; transistor MESFET; AWR Microwave Office

\begin{abstract}
:
This paper provides a detailed description and all the procedures involved in designing a power amplifier using microstrip technology and the design software Microwave Office ${ }^{\mathrm{TM}}$. Specifically, the design is oriented to build an amplifier with central frequency at $14 \mathrm{GHz}$, but the same fundamentals and principles could be applied in the whole range of radio frequency. For the design, a MESFET transistor and simultaneous input and output matching networks are considered. The values of the parameters and the simulation for every stage are computed and performed using AWR Microwave Office ${ }^{\mathrm{TM}}$. At the end of the document, a fully functional circuit layout represented in $2 \mathrm{D}$ and $3 \mathrm{D}$ is shown with all their complementary elements.
\end{abstract}

Keywords: power amplifier; matching networks; microstrip; MESFET transistor; AWR Microwave Office

\footnotetext{
${ }^{1}$ Escuela Politécnica Nacional, Quito - Ecuador (\{christian.tipantuna, jose.estrada\}@epn.edu.ec)

2 Corporación Nacional de Telecomunicaciones, Quito - Ecuador (jancoej@gmail.com)

${ }^{3}$ Escuela Politécnica Nacional - Estudiante, Quito - Ecuador (carlaparra6@hotmail.com)
} 


\section{Introduction}

In order to cover large distances and to provide a suitable signal power level, the amplification stage is a very important component in a communication system, and especially in wireless communications (Pirola, Teppati, \& Camarchia, 2007). A lot of information and literature is available with respect to the design for low frequency amplifiers (i.e. for frequencies lower than 300 $\mathrm{KHz}$ ). The design of these amplifiers considers lumped components. On the other hand, the description of our design is for a higher frequency and it uses distributed components (rather than lumped components) through the use of microstrip technology (Raab, Asbeck, Cripps, \& Sokal, 2002).

For performing microwave implementations basically there are two options, which are: using planar circuits (based on microstrip technology), and using waveguide circuits. Now a days, planar circuits are a trend because of their low cost and small size in comparison with the large size and cost of a microwave implementation.

Microstrip technology is currently used in a plenty of RF and microwave design applications. Elements such as: antennas, amplifiers, couplers, splitters, diplexers and other devices are built using microstrip technology because it has some significant characteristics such as small size and lightweight. In addition, respect to planar implementations i.e. implementations based on microstrip at the same time there are two options: hybrid and monolithic implementations, and the differences between two technologies are shown in the Table 1 (Pirola, 2012).

Table 1. Comparison of hybrid and monolithic implementations

\begin{tabular}{|c|c|}
\hline MMIC - Monolitic Microwave Integrated \\
Circuits & HIC - Hybrid Integrated Circuits \\
\hline Cheap in large quantities & Simple circuits can be cheap \\
\hline Very good reproductibility & $\begin{array}{c}\text { Poor reproducibility: device } \\
\text { placement / bond wires } \\
\text { Reliable }\end{array}$ \\
$\begin{array}{c}\text { Mostly "glued" together and so } \\
\text { reliabilities suffers }\end{array}$ \\
\hline Space is premium; must be as small as \\
possible & $\begin{array}{c}\text { Substrate is cheap, micro-strip to } \\
\text { be used abundantly }\end{array}$ \\
\hline Long turn-around-time (3 months) & $\begin{array}{c}\text { Can be very fast, making } \\
\text { redesigns easy }\end{array}$ \\
\hline
\end{tabular}

Both implementations MMIC and HIC are cutting edge technologies and they have a good performance, but in our current design has been considered the hybrid implementation due its low cost and because it is easier to build. Furthermore, to build MMIC circuits is needed very expensive and sophisticated materials and machineries, for this reason in an eventual implementation of our design, this option (MMIC) has a low probability to be implemented.

In the design of RF and microwave devices and components, it is very important to have an accurate and sophisticated tool both for the calculations and the simulation. Currently, there are some good tools to perform these activities such as Agilent Advanced Design Software ADS, AWR 
Microwave Office and others (Alabaster). The tool selected for this work was AWR Microwave Office (MWO) because it offers a friendly environment in comparison with other tools and also due to the availability of licenses at the campus of Politecnico di Torino.

\section{Parameters and requirements}

As mentioned at the beginning of this paper, our purpose is to describe a generic process for the design of a power amplifier; however, in this case and to show the rest of the processing in the next sections, the parameters of the current design are shown below in Table 2.

Table 2. Parameters and requirements for the design.

\begin{tabular}{|c|c|}
\hline \multicolumn{2}{|c|}{ General Characteristics - Power Amplifier } \\
\hline Parameter & Value / Type \\
\hline Central Frequency & $14 \mathrm{GHz}$ \\
\hline Transistor & Type MESFET \\
\hline \multicolumn{2}{|c|}{ Microstrip characteristics } \\
\hline Parameter & Value $/$ Type \\
\hline Metal & Copper, thickness $15 \mu \mathrm{m}$ \\
\hline Teflon & $\varepsilon r=2.08$, thickness $0.5 \mathrm{~mm}, \mathrm{tg}(\delta)=4 \mathrm{e}-4$ \\
\hline
\end{tabular}

\section{Design and Methodology}

The first step consists on checking the behavior and the characteristics of the active element, i.e. the MESFET transistor, then the transistor gain and finally the input and output matching networks. In the next sections we make a deeper explanation of these topics.

In our design has been used a MESFET transistor due to its availability, but this is not the unique option, in the Table 3, are shown in a brief description the different options according to the materials (Pirola, 2012).

Table 3. Materials and devices in RF and microwave electronics

\begin{tabular}{|c|c|}
\hline Materials and devices & Characteristics \\
\hline Silicion IC's Mosfet and bipolars & Ok up to 5-10 $\mathrm{GHz}$ but not for power \\
\hline $\begin{array}{c}\text { Silicon-Germanium (SiGe) Heterojunction } \\
\text { Bipolar Transistors (HBT) }\end{array}$ & $\begin{array}{c}\text { Low noise and low power up to } 40 \mathrm{GHz} \\
\text { Up to } 50 \mathrm{GHz} \text {, also for high power }\end{array}$ \\
\hline GaAs IC's (MESFETs and HEMTs) & $\begin{array}{c}\text { High power up to } 30 \mathrm{GHz} \text {, not yet } \\
\text { mature }\end{array}$ \\
\hline GaN (HEMTs) & $\begin{array}{c}\text { Low noise up to mm waves, not yet } \\
\text { mature }\end{array}$ \\
\hline GaSb (HEMTs) & \\
\hline
\end{tabular}

\subsection{Checking the stability}

First of all, the stability of the transistor needs to be checked. To do that, two conditions have to be verified, the first condition is that the stability coefficient being greater than one $(K>1)$, where:

$$
K=\frac{1-\left|S_{11}\right|^{2}-\left|S_{22}\right|^{2}+\left|\Delta_{S}\right|^{2}}{2\left|S_{21}\right|\left|S_{12}\right|}
$$


The second condition is that the module of the determinant of scattering matrix (S) being lower than $1(|\Delta S|<1)$, where:

$$
\Delta_{s}=S_{11} S_{22}-S_{12} S_{21}
$$

All the different $\mathrm{S}$ parameters, $\mathrm{S}_{11}, \mathrm{~S}_{12}, \mathrm{~S}_{21}, \mathrm{~S}_{22}$, as well as, the stability coefficient $\mathrm{K}$ and the determinant $\Delta_{S}$ are computed using MWO.

To check the stability it is also useful to have the information provided by the scattering matrix obtained from the transistor MESFET (FET2_1 in simulation). The scattering matrix of the transistor and the different graphs are obtained through MWO. The schematic needed to compute both the matrix $S$ and the determinant is the shown in Fig. 1, where the 50 ohms impedance on both input and output corresponds to the requested values of the input and output matching networks. The schematic shown in the Figure 1, is a starting point of the design and it is suggested in some literature as in (Pirola, Teppati, \& Camarchia, 2007) and (Camarchia, Teppati, Corbellini, \& Pirola, 2007).

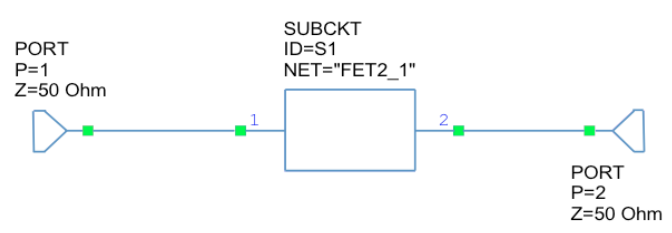

Figure 1. Schematic to check the stability (scattering parameters FET2_1)

Both, $\mathrm{K}$ and $|\Delta S|$ fulfill with the conditions mentioned above, and their different values in a region of analysis from $5 \mathrm{GHz}$ to $25 \mathrm{GHz}$ are shown in Figure 2.

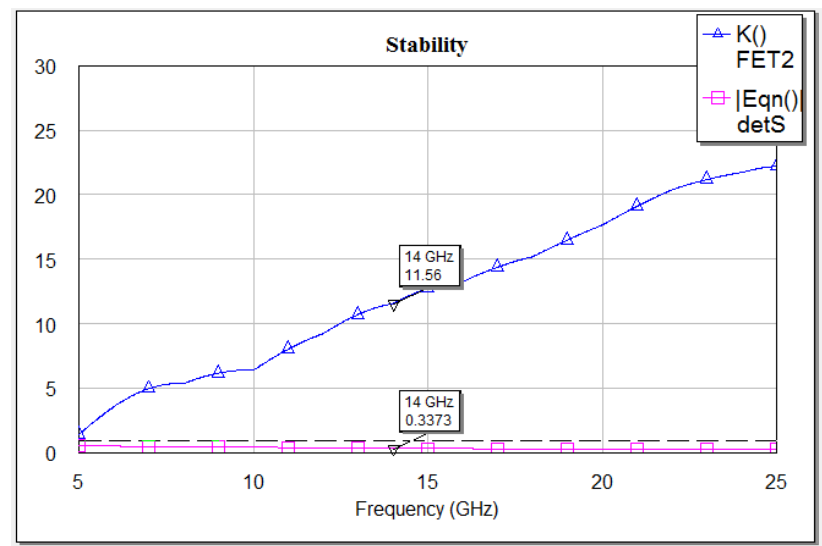

Figure 2. $\mathrm{K}$ and $|\Delta \mathrm{S}|$ to check the stability

\subsection{Transistor Gain}

In order to know the behavior of the active element (transistor FET2), it is also suggested to check the power gains, the MAG Maximum Available Gain (the maximum gain GMax), and $\left|S_{21}\right|$, which is the gain when the device is close on both ports with the normalization impedance $(50 \Omega)$. Both gains in $\mathrm{dB}$ are shown in the Figure 3. 


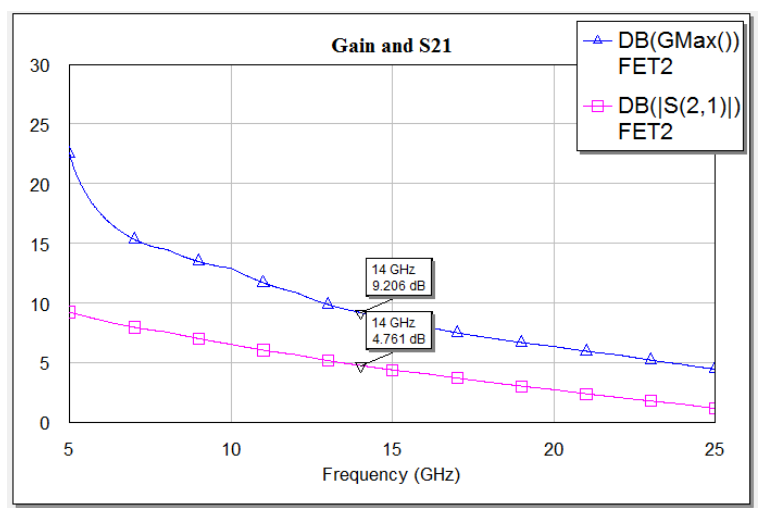

Figure 3. GMAX and $\mathrm{S}_{21}$ of Transistor FET2

In Figure 3, it can be noted that the device behavior is linear (stability condition) in terms of gain. Now, based on the analysis from Fig. $2(K>1$ and $|\Delta S|<1)$ and observing the Fig 3., it is noted that when the device is working in a range of frequencies between $5 \mathrm{GHz}$ and $25 \mathrm{GHz}$, and of course in $14 \mathrm{GHz}$, it has a behavior "unconditionally stable". In addition, Fig. 3 shows that the maximum device gain at $14 \mathrm{GHz}$ is $\mathrm{Gmax}=9.206 \mathrm{~dB}$, and $\left|\mathrm{S}_{21}\right|=4.7161 \mathrm{~dB}$, i.e. $\mathrm{S}_{21}<\mathrm{Gmax}$; at end of design it is expected to get $\mathrm{Gmax}=\mathrm{S}_{21}$ at $14 \mathrm{GHz}$. The maximum power transfer occurs when the generator yields the maximum power, i.e. the input power is the generator (input) available power and the power on the load is the output available power. The maximum power transfer implies power impedance matching simultaneously at the input and output (if this is possible). The maximum operational gain is:

$$
G_{\text {opmax }}=\left|\frac{S_{21}}{S_{12}}\right|\left(K-\sqrt{K^{2}-1}\right)
$$

Furthermore, to completely understand the behavior of the device, it is convenient to plot the constant gain circles and the stability circles. According to the gain circles, GOP circle (GOP: operating gain - Gamma $L$ ) is respect to output, and GAV circle (GAV: available gain - Gamma G) is respect to input, see Figure 4 (Teppati, Ferrero, Pisani, Colantonio \& Limiti, 2005). 


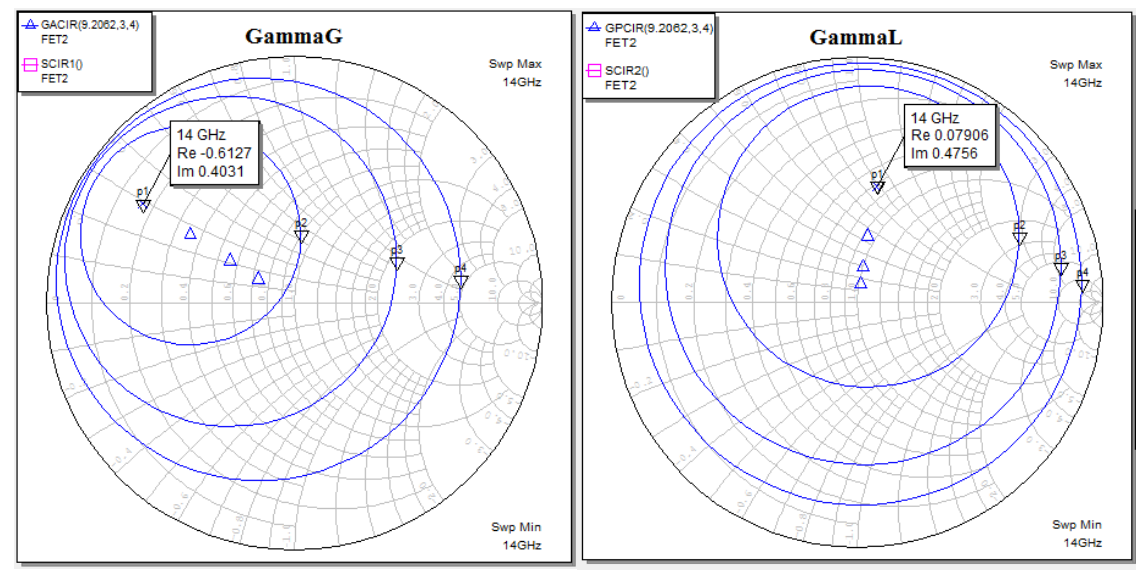

Figure 4. Constant gain circle $\Gamma_{G}$ and Constant gain circle $\Gamma_{L}, f=14 \mathrm{GHz}$

As it is expected, the stability circles (SCIR 1 and SCIR 2) do not appear since the element (transistor) is "unconditionally stable". Meanwhile in the analysis of the gain circles, it is verified that there is a maximum in the plane $\Gamma G$ for $G A V$ and a maximum in $\Gamma L$ for GOP. These maximum values correspond to optimum values $\Gamma \mathrm{G}$ opt. and $\Gamma \mathrm{L}$ opt., It can be noted that MWO is able to directly compute the value of $\Gamma \mathrm{G}$ opt, and $\Gamma L$ opt.. MWO define these parameters as GM1 ( $\Gamma \mathrm{G}$ opt ) and GM2 (ГL opt.). In Table 4, it can be noted the complex values of $\Gamma G$ opt. and $\Gamma L$ opt.; these values of GM1 and GM2 expressed in magnitude and angle will be very useful for the design of the matching networks as it will be shown later.

Table 4. GM1 and GM2 at $14 \mathrm{GHz}$.

\begin{tabular}{|c|c|c|c|c|}
\hline \multirow{2}{*}{ GM } & \multicolumn{4}{|c|}{$\begin{array}{c}\text { GM1 and GM2 in magnitude and angle } \\
\text { for the matching networks }\end{array}$} \\
\cline { 2 - 5 } & Real & Imaginary & Magnitude & Angle \\
\hline GM1 & $-0,61361$ & 0,40344 & 0,73436 & 146,68 \\
\hline GM2 & 0,07789 & 0,47437 & 0,48073 & 80,674 \\
\hline
\end{tabular}

GM1 and GM2 indicate that working with the current active device in a given frequency (e.g. 14 $\mathrm{GHz}$ ), and considering $50 \Omega$ of input and output impedance, there are only two passive loads, one at the input port (GM1), and the other at the output port (GM2) that ensure the simultaneous match at the two ports of active device (MESFET), hence now the task consists in designing two lossless matching networks.

\subsection{Design considerations and simultaneous matching networks}

Considering that the design consists of making an amplifier that works with maximum gain, it is necessary to design the corresponding lossless matching networks, remembering that a two-port unconditionally stable system can be simultaneously matched at both ports. In this case, all the power will be transferred from generator (maximum power) to the load ZL, i.e. GOP = GAV = GMAX; in other words, when the device sees GM1 at the input port, and GM2 at the output port, it achieves the maximum gain GMAX (i.e. $\left|S_{21}\right|=G m a x$ ). 
Considering the active device (transistor) and the input and output matching network, the general scheme of the desired amplifier is shown below in Figure 5, (Camarchia, Teppati, Corbellini, \& Pirola, 2007).

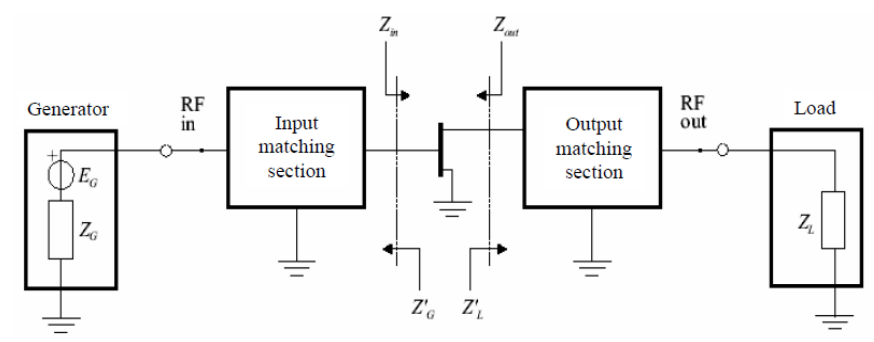

Figure 5. RF Amplifier with simultaneous matching networks

In order to implement the input and output matching networks, it is necessary to work with conjugate values of GM1 and GM2, so as to eliminate the imaginary parts of GM1 and GM2, as it is show in Table 5 and in Figure 6, i.e. the matching network is a conjugate matching of an active two-port device.

Table 5. GM1 and GM2 conjugate.

\begin{tabular}{|c|c|c|}
\hline GM & Magnitude & Angle \\
\hline GM1 & 0,73436 & 146,68 \\
\hline GM2 & 0,48073 & 80,674 \\
\hline GM1 $^{*}$ (conjugate) & 0,73436 & $-146,68$ \\
\hline GM2* $^{*}$ (conjugate) & 0,48073 & $-80,674$ \\
\hline
\end{tabular}
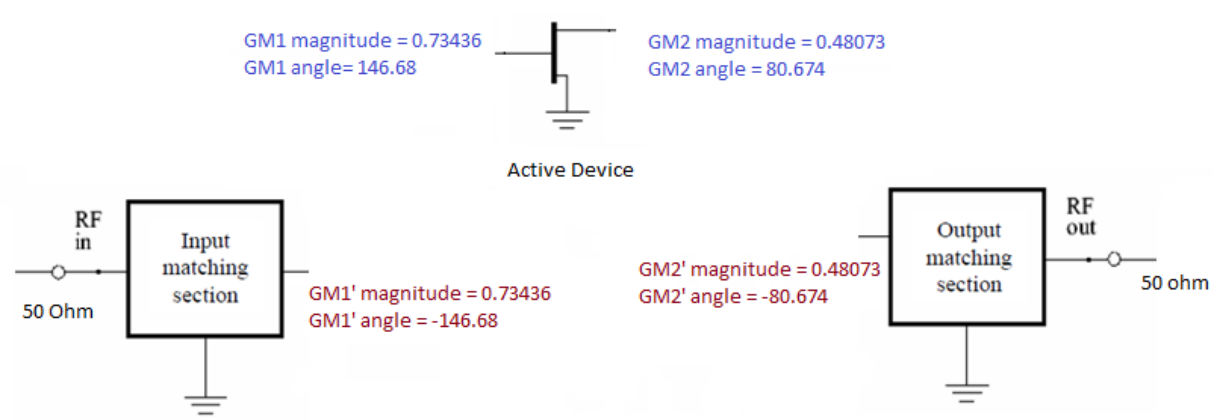

Figure 6. Specifications $\mathrm{GM} 1^{*}$ and $\mathrm{GM} 2^{*}$, matching networks

When the matching condition is satisfied, $S_{11}$ and $S_{22}$ of the amplifier will be zero and $\left|S_{21}\right|=$ GMAX. Now, all the considerations to design the matching networks are available, but before, some parameters in MWO have to be configured, as it is done below.

\subsection{Design considerations in MWO}

The design must be implemented using microstrip lines, whose parameters (substrate and metal) are described in Table 1 and shown in Figure 7.

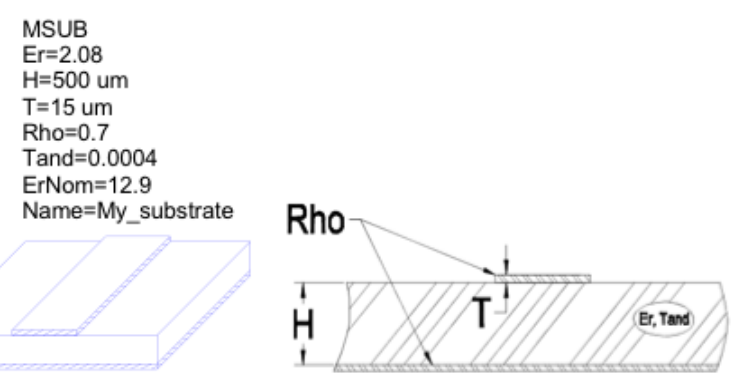


Figure 7. Design parameter microstrip lines

Remembering that resistivity of the metallization (Rho) is normalized to gold, for copper its value is:

$$
\text { Rho }=\frac{\text { copper resistivity }}{\text { gold resistivity }}=\frac{1,67 \times 10^{-8} \Omega m}{2,35 \times 10^{-8} \Omega m}=0,7
$$

The TXLINE tool of MWO (Figure 8) will be used with the amplifier data to automatically get the width and the physical length for the transmission line. In particular, for this design we considered a fixed width, while the parameter that could change is the physical length.

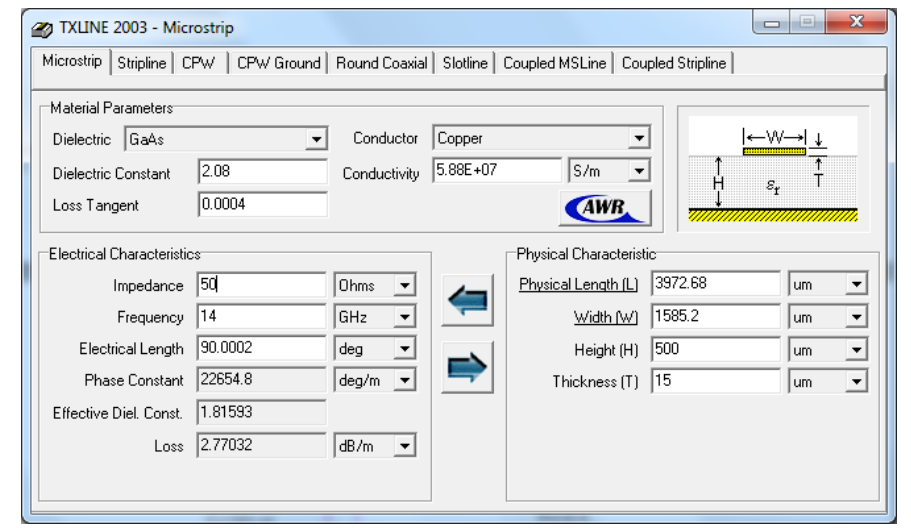

Figure 8. Calculation of width and initial length of the microstrip lines using TXLINE TOOL

\subsection{Matching networks: Input matching network}

In the design of the input and output matching networks we considered not only the microstrip lines, but also a serial short circuit stub, i.e. the input and the output are composed by the transmission lines and the stubs (Raab, Asbeck, Cripps, Kenington, Popović, Pothecary \& Sokal, 2002).

The desired values of resistance and reactance are obtained with microstrip lines and short-circuit stubs. The aim at the moment is to couple the input and output networks by modifying certain parameter, in this case the physical length of the line and stub. The modification and all necessary changes in the length do not matter because establishing the goals and using optimizer all changes are performed automatically and then these can be tested using Smith chart or other kind of graphs. In general the scheme of the amplifier looks like as the shown in the Figure 9. 


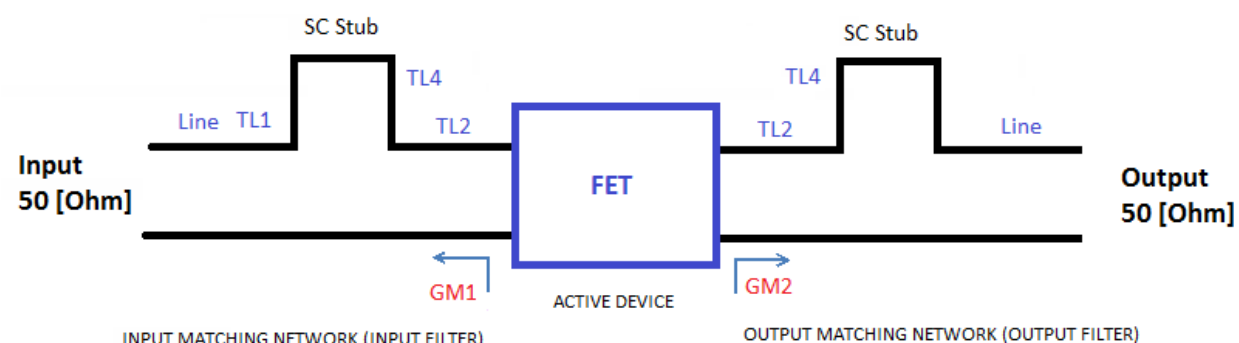

Figure 9. Amplifier diagram included short circuit stubs

For the design,the width of the transmission line has been considered as a fixed parameter $(\mathrm{W}=$ $1585 \mathrm{um}$ ) and the variable parameter is the physical length (TL2 and TL4 for the input and the output network, see Fig.9). By means of the optimizer tool of MWO, the best dimensions of the length to satisfy the goals and needs is obtained automatically. The first step is to set the goal for the matching network, in this case the goal is to minimize the $S_{11}$ (reflection coefficient) in order to transfer the maximum power from the generator toward the load, so, it is set to $\left|S_{11}\right|<-30 \mathrm{~dB}$ and in a range of frequencies between $13.8 \mathrm{GHz}$ and $14.2 \mathrm{GHz}$ (central frequency at $14 \mathrm{GHz}$ ), in particular narrow band design has been considered because it is less complex.

Once the goal is established, we have to select the parameters to be optimized (variables). For the input matching network, the physical length of TL2 and TL4 are the parameters to be optimized, then the optimizer is run with the desired values according to the established goal. Furthermore, the size of the elements has been constrained to avoid negative values (Lower $=100$ um, Upper=9000 um).

Finally, the input matching network (input filter) is obtained using all the elements and dimensions. Its scheme is shown in Figure10.

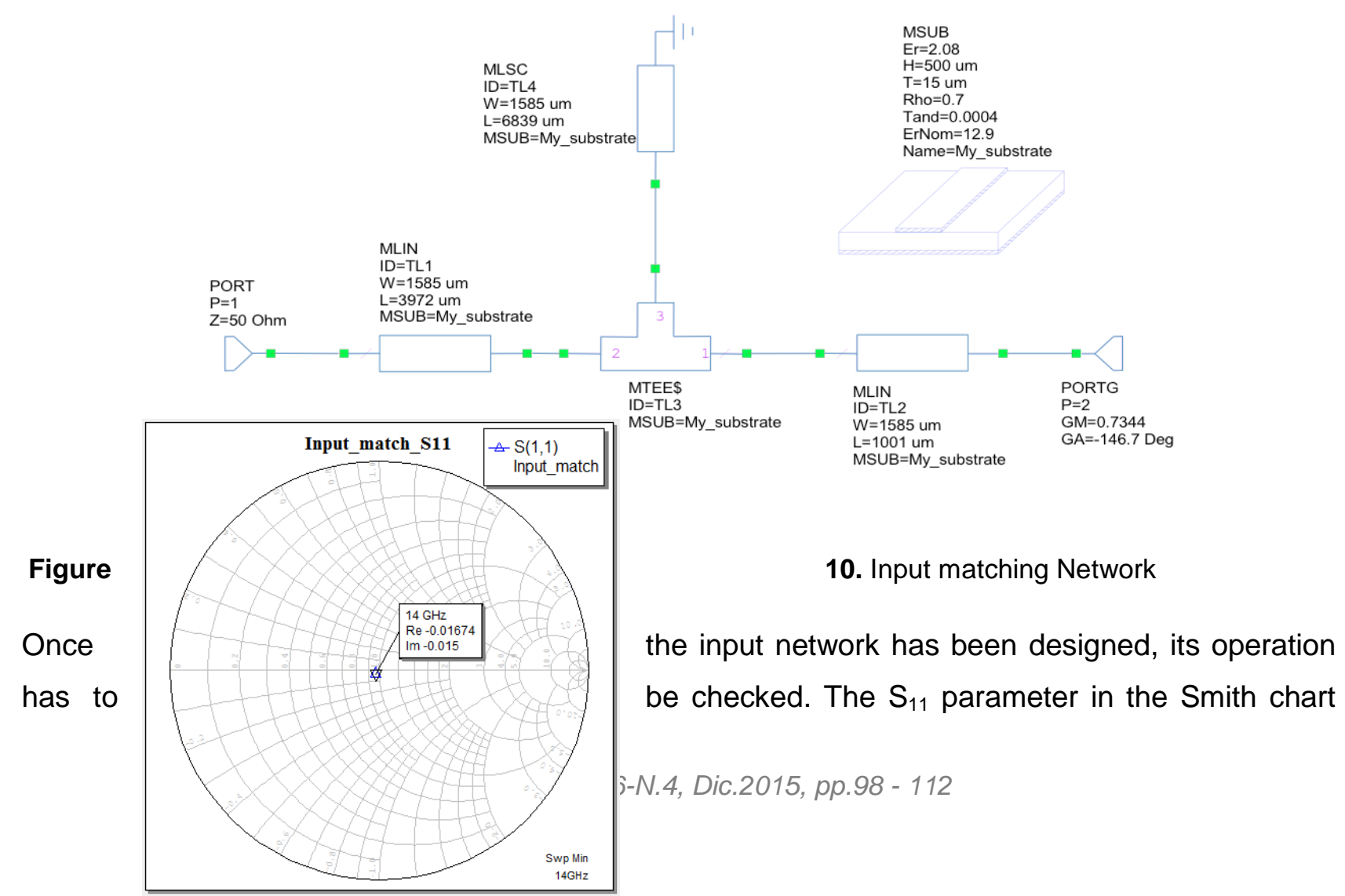


and in a rectangular graph give enough details of the behavior of the input network and the fulfillment of the goal $\left(\left|S_{11}\right|<-30 \mathrm{~dB}\right)$, see Figure 11 .

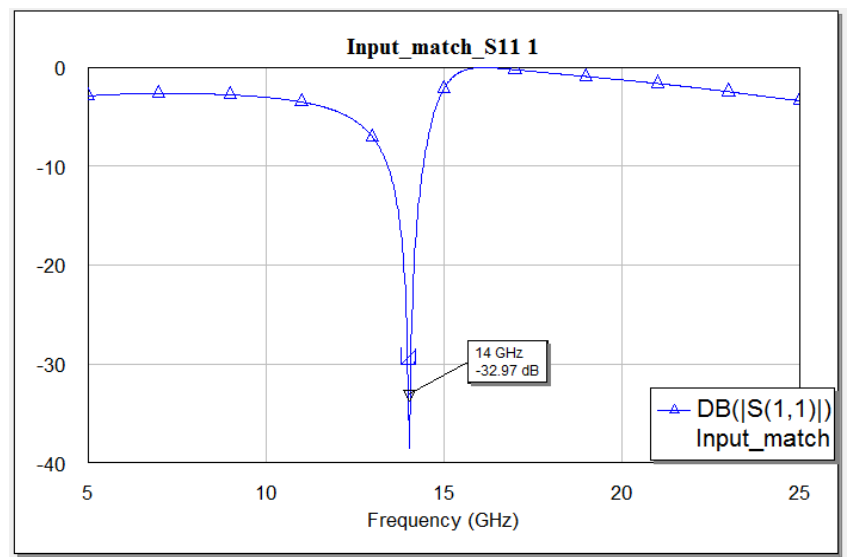

Figure 11. Input reflection coefficient in Smith Chart and $\left|S_{11}\right| d B$ in rectangular graph ( $\left.f=14 \mathrm{GHz}\right)$

Analyzing Fig. 11, it can be noted that the design of the input matching network has been completed successfully, since $\left|S_{11}\right| \mathrm{dB}$ is lower than the fixed goal $\left(\left|\mathrm{S}_{11}\right|=-32.97 \mathrm{~dB}\right)$ and the reflection coefficient is 0 (real $=-0.01664$, imaginary $=-0.015)$.

\subsection{Matching networks: Output matching network}

As before in this case, the goal is $\left|S_{11}\right|<-30 \mathrm{~dB}$, and the variables to optimize are TL2 and TL4. Following the same procedures as in the input matching networks, the results obtained are shown below, see Figure 12.

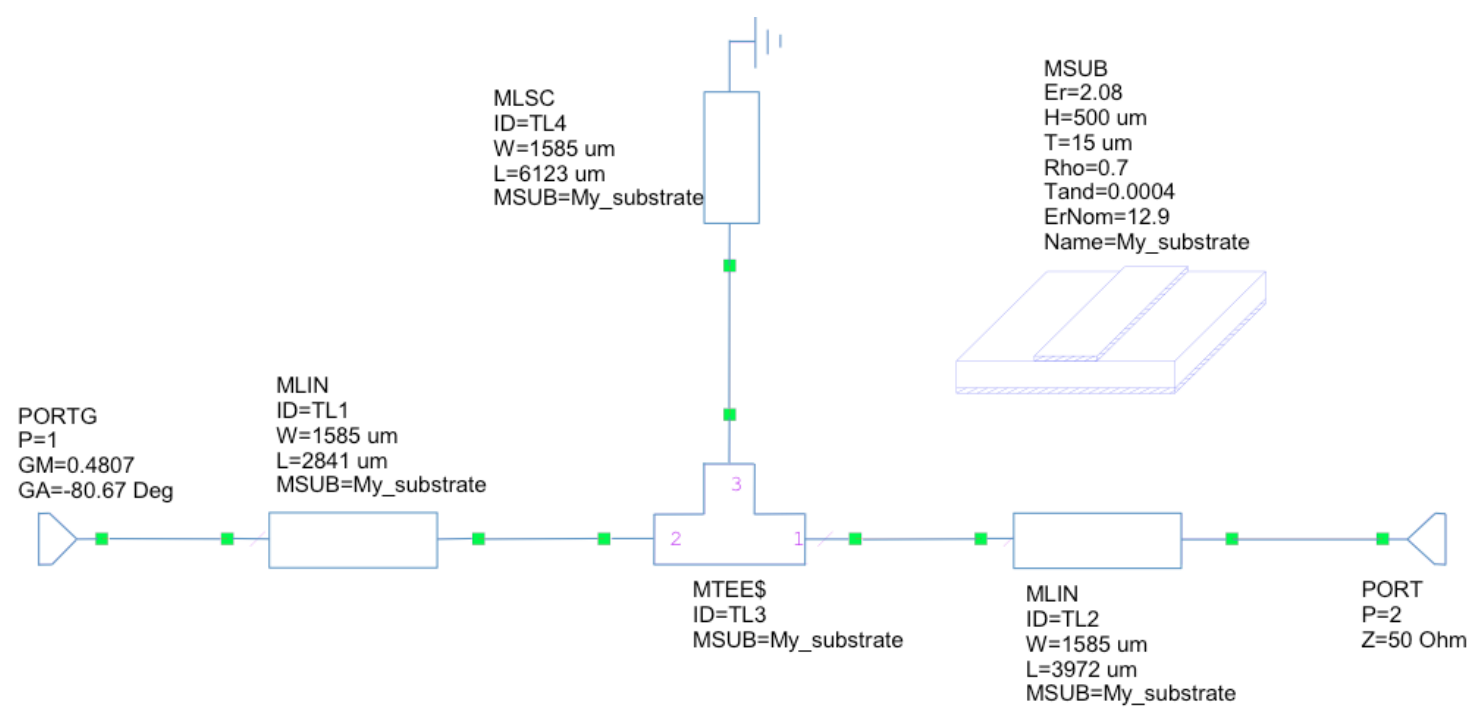

Figure 12. Output matching Network 

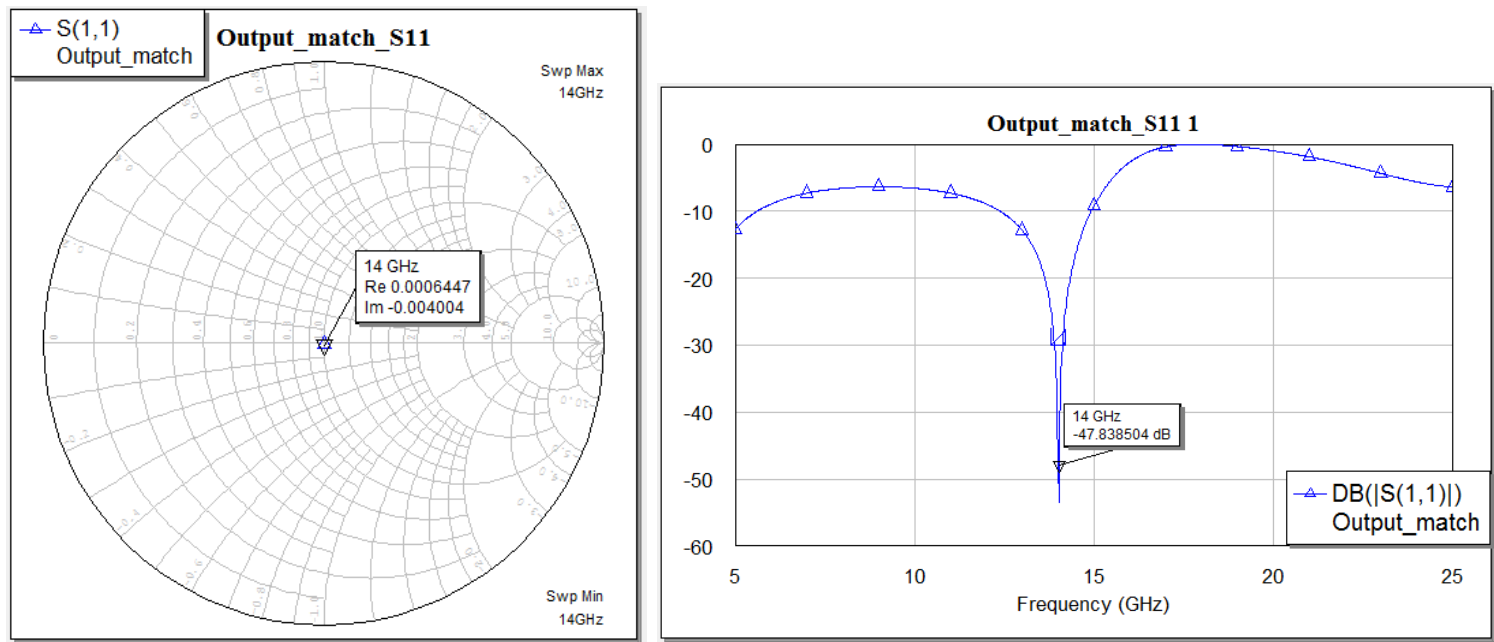

Figure 13. Output reflection coefficient and $\left|S_{11}\right| d B$ in rectangular graph ( $f=14 \mathrm{GHz}$ )

Analyzing Figure 12 and Figure 13, it can be concluded that the design of the output matching network has been completed successfully, since $\left|S_{11}\right| d B$ is lower than the fixed goal $\left(\left|S_{11}\right|=-\right.$ $47.838504 \mathrm{~dB}$ ) and the reflection coefficient is 0 (real= -0.0006447 , imaginary $=-0.004004)$.

\section{Results}

Up until this point, both networks, input and output, are designed and they need to be combined with the active element. The whole amplifier is shown in Figure 14.

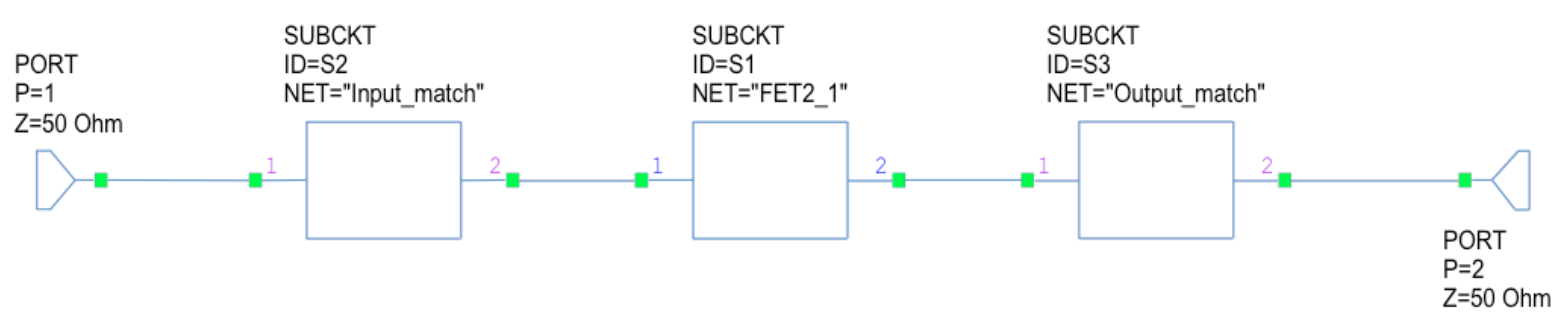

Figure 14. Diagram of amplifier - composed by 3 subcircuits

Of course, and as stated above, it is necessary to evaluate the behavior and the performance of the amplifier in terms of reflection coefficient and gain.
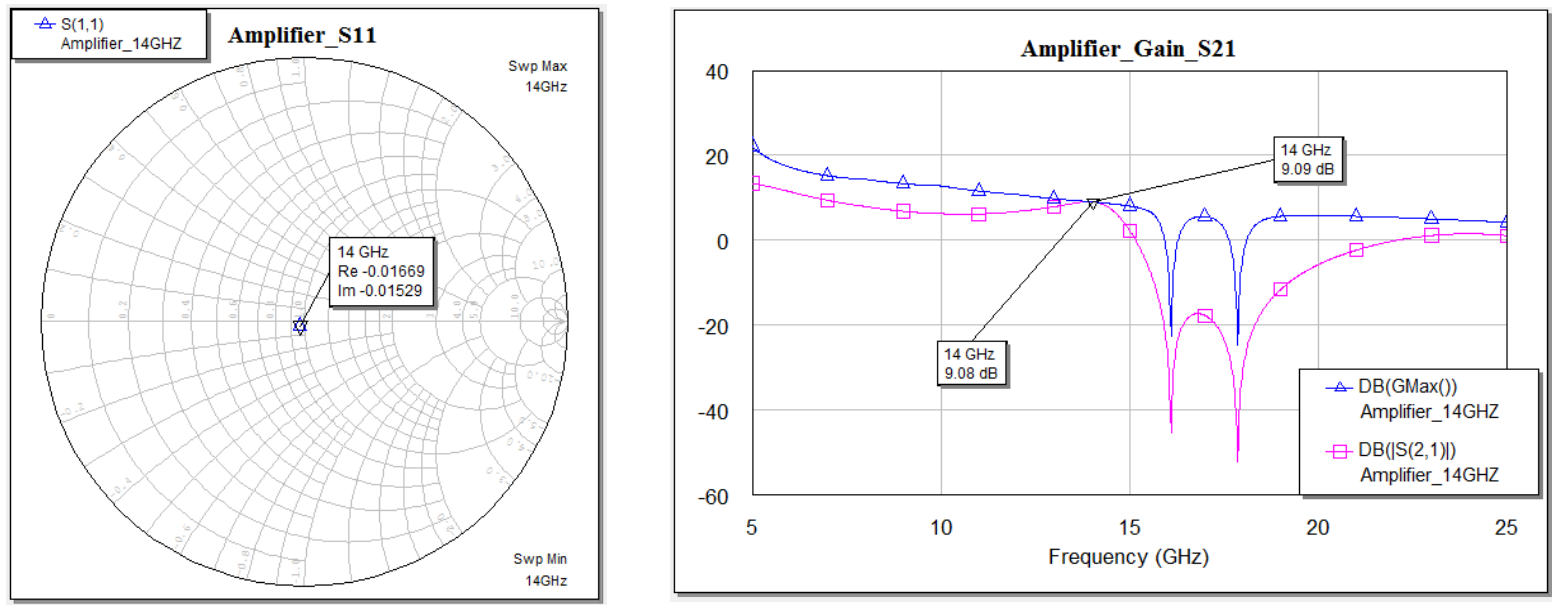

Figure 15. Reflection coefficient of amplifier, maximum Gain and $\mathrm{S}_{21}(\mathrm{f}=14 \mathrm{GHz})$ 
Analyzing the graphs of Figure 15, it can be concluded that the objective of designing an amplifier at $14 \mathrm{GHz}$ with maximum gain has been fulfilled. Finally, appropriate lossless matching networks help to build amplifiers providing maximum power (GMAX), as illustrated in Figure 15 that shows that $S_{21}=$ GMAX at $14 \mathrm{GHz}$ and $S_{11}$ and $S_{22}$ (input and output reflectionn coefficients) are very small values (under $-30 \mathrm{~dB}$ ).

\subsection{Layout of the amplifier}

Having designed the amplifier, is very easy to get its layout. MWO gives the possibility to plot 2-D or 3-D layouts, with the option "layout". Taking in mind that the amplifier contains an active device (transistor), it is necessary to consider a power supply in the design (BIAS), and capacitors in the input and in the output to block the DC component (Camarchia, Moreno, Pirola, Quaglia \& Wegeland, 2013), so the final implementation of the amplifier looks like the shown in Fig. 16, (Kawai, Ohta \&

Enokihara, 2010).

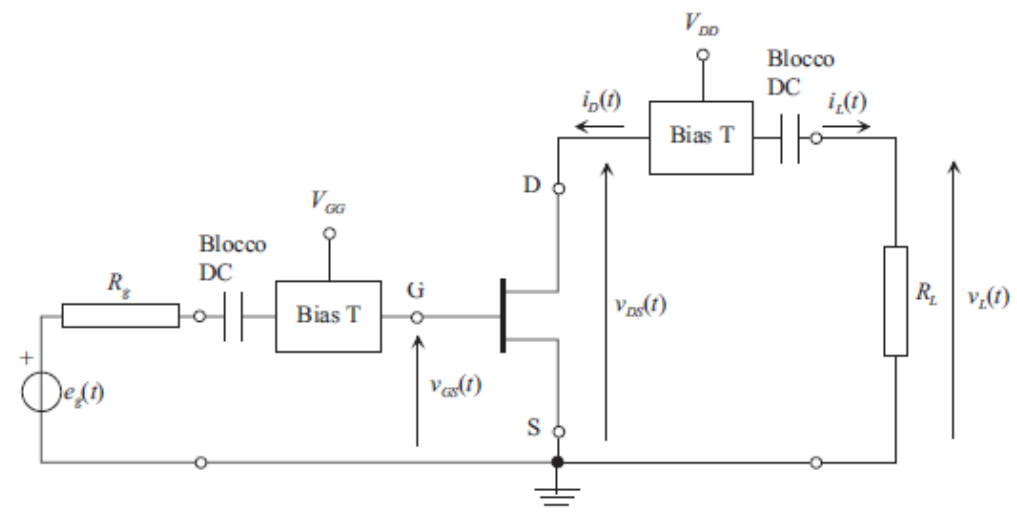

Figure 16. RF amplifier considering a power supply

In order to obtain the final layout, the scheme will change a little due to the association of the different elements (transistor, capacitors). The bias capacitor value was calculated based on the consideration about the work frequency, taking into account that the capacitor should act as a short circuit at $14 \mathrm{GHz}$ of frequency, and that:

$$
X_{c}=\frac{1}{2 \pi f C}
$$

The value of the capacitor is $22 \mathrm{pF}$ and the amplifier with all additional elements is the shown in the Figure 17, it is shown a layout in 2-D and 3-D. 


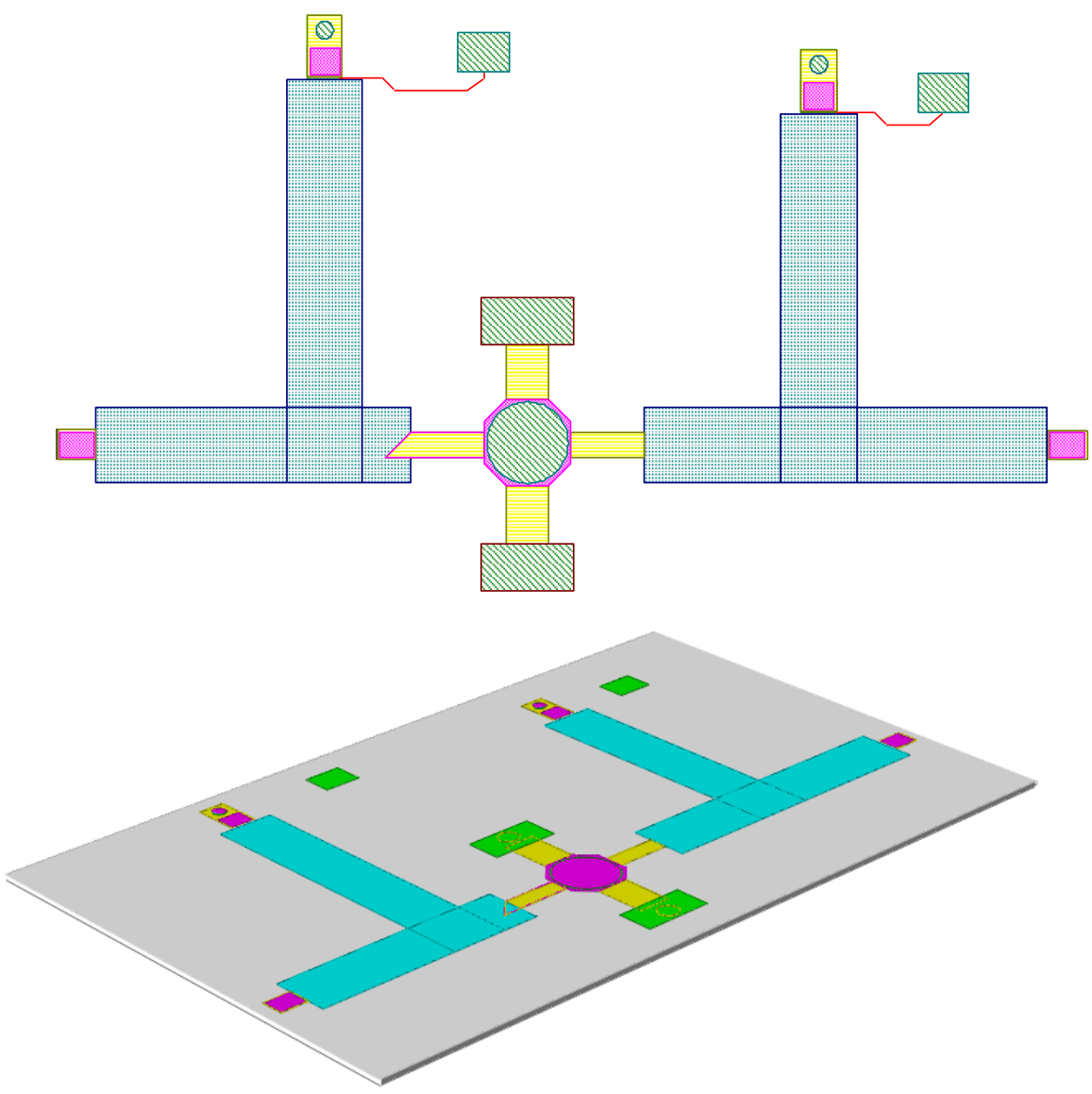

Figure 17. Amplifier layout 2-D and 3-D

\section{Conclusions}

Analyzing all the graphs above, we conclude that the objective of designing an amplifier at $14 \mathrm{GHz}$ with the maximum gain has been fulfilled. With the support of MWO, the processes were achieved in a more simple way, but all the processes need to be performed in the correct order and with coherence to obtain the best results. The steps and procedures above could be used in other designs since the principles and the considerations done for the design wew generic and not oriented to a particular frequency or transistor. A correct preliminary analysis of the matching networks is very useful and necessary in order to obtain the maximum available gain of the transistor. A plenty of choices are possible to match the impedance of the transistor and to choose the correct one it is necessary to consider the physical length and the final size of the amplifier.

Microstrip technology provides tremendous advantages regarding the design. Some elements such as amplifiers, matching networks, couplers, diplexers and a lot microwave devices could be implemented using microstrip technology, and this technology has some advantages, which are mainly the little space these devices need and their reduced weight.

The traditional design is a good starting point to have an idea of the goals and the expected behavior of the amplifier; however, the active element i.e. the transistor, the parameters and the 
characteristics are totally different. Indeed, the design itself is different, so all the steps described above are a suggested path to follow in the design of power amplifiers or other RF devices.

Currently, software tools such as AWR Microwave Office or ADS are, without doubts, very helpful, but furthermore it is needed to have a clear idea of the goals, purposes and application of the design. With a suitable methodology and fundamentals it is possible to start with the basics and to continue to more complex systems.

\section{Acknowledgment}

This work was done with the support from Prof. Marco Pirola, professor of Devices and Technologies in Mobile Communication Systems at Politecnico di Torino, Turin, Italy.

\section{Bibliografía}

Pirola, M., Teppati, V., \& Camarchia, V. (2007). Microwave measurements Part I: Linear Measurements. Instrumentation \& Measurement Magazine, IEEE, 10(2), 14-19.

Camarchia, V., Teppati, V., Corbellini, S., \& Pirola, M. (2007). Microwave measurements part II non-linear measurements. Instrumentation \& Measurement Magazine, IEEE, 10(3), 34-39.

Raab, F. H., Asbeck, P., Cripps, S., Kenington, P. B., Popović, Z. B., Pothecary, N., ... \& Sokal, N. O. (2002). Power amplifiers and transmitters for RF and microwave. Microwave Theory and Techniques, IEEE Transactions on, 50(3), 814-826.

Teppati, V., Ferrero, A., Pisani, U., Colantonio, P., Giannini, F., \& Limiti, E. (2005). Load - Pull Techniques. Encyclopedia of RF and Microwave Engineering.

Kawai, T., Ohta, I., \& Enokihara, A. (2010, December). Design method of lumped-element dualband Wilkinson power dividers based on frequency transformation. In Microwave Conference Proceedings (APMC), 2010 Asia-Pacific (pp. 710-713). IEEE.

Eliasson, R., Sundberg, A., \& Wall, A. (2007). ADAPTATION OF A GMIC PROCESS TO MICROWAVE OFFICE USING A PROCESS DEVELOPMENT KIT FROM APPLIED WAVE RESEARCH. Microwave Journal, 50(3).

\section{Alabaster, C. COMPARISON OF SOFTWARE TOOLS FOR THE DESIGN OF MICROWAVE COMPONENTS.}

Camarchia, V., Moreno Rubio, J. J., Pirola, M., Quaglia, R., Colantonio, P., Giannini, F., ... \& Wegeland, T. (2013). High-efficiency $7 \mathrm{GHz}$ Doherty GaN MMIC power amplifiers for microwave backhaul radio links. Electron Devices, IEEE Transactions on, 60(10), 3592-3595. 
Pirola, M., (2012). Introduction to RF and microwave integrated circuits. Advanced Theory and Technology of Devices. Masters course. Master in Wireless Systems and Related Technologies. Politecnico di Torino. 